\title{
A Dynamic Integrative Web Environment for Computational Chemistry
}

\author{
Morella Sánchez, Alexander Peraza, Víctor Sojo, Eleazar Matheus, \\ Ernesto Coto, Miguel Fernández, Rhonald López, Marbelia López \& \\ Fernando Ruette
}

IVIChem é um sistema de interface gráfica de utilizador baseada na web que melhora usabilidade de softwares de química computacional (QC), como o GAMESS, DeMon2k, o DeMon-nano, MOPAC e CATIVIC. Aqui, as instalações de entrada e análise dos resultados foram aplicadas para analisar a estrutura eletrônica, interação molecular e rotas de eventos de superfície. Esta interface facilita a construção de geometrias moleculares, montagem de arquivos de entrada, sequência de espera de cálculo, monitoramento do status dos cálculos e análise gráfica dos resultados. A possibilidade de incorporar novos pacotes computacionais de química, por especialistas ou criadores de software, também é considerada. É importante mencionar que IVIChem é focado na utilização de software, não proprietário e multidisciplinar, sendo empregado em diferentes áreas de modelagem de química.

Palavras-chave: IVIChem, interface para usuário, química computacional, usabilidade, GAMESS, DeMon2k, DeMon-nano, MOPAC, CATIVIC.

IVIChem is a web-based graphical user interface system that improves usability of computational chemistry (CC) software, such as GAMESS, DeMon2k, DeMon-nano, MOPAC, and CATIVIC. Here, input facilities and analysis of results were implemented to examine electronic structure, molecular interaction, and routes of surface events. This interface facilitates the construction of molecular geometries, assembling input files, job submission to a calculation queue, monitoring the status of calculations, and graphical analysis of results. The possibility to incorporate new computational chemistry packages by experts or software creators is also considered. It is important to mention that IVIChem is focused in the use of multidisciplinary non-proprietary software employed in different areas of chemical modeling.

Keywords: IVIChem, user interfaces, computational chemistry, usability, GAMESS, DeMon2k, DeMon-nano, MOPAC, CATIVIC. 


\section{Introduction}

Internet technology offers remarkable opportunity for the development of computational tools by the cooperative effort of various groups and institutions. It is possible to solve new scientific problems in multidisciplinary fields with the assistance of CC including in some cases computational physics and simulation software for engineering processes. In order to make fast advances, it is of vital importance to build tools that provide a common web interface for end users with the aim of tackling a variety of technical problems. Furthermore, software creators require an available interface to include their novel calculation packages and new computational instruments for analysis of results that will perk up the $\mathrm{CC}$ modeling performance of research groups worldwide.

Few CC free packages are built with efficient user interfaces. Most of those that have one are proprietary software (PS) that involves expensive and restrictive licenses, with permissions limited to only one or a few machines. Thus, researchers and academic institutions that do not have the possibility to buy PS are at a clear disadvantage.

Applications of $\mathrm{CC}$ involve a complex mix of rising methodologies, improved predictive theories, and strategic procedures applied to scientific and technologically challenging problems. As an example, a draft scheme of an interface with several disciplines related with modeling of engineering processes is presented in Fig. 1. The usability of free CC software is generally poor, making research difficult for both beginners and experts $^{1-2}$. An adequate solution to facilitate a general use of free CC software is the construction of an integrative web environment of graphical user interfaces that can be accessed worldwide from any typical computer.

\section{Computational Software}

In a previous communication ${ }^{3}$, we only have included semi-empirical calculation packages CATIVIC ${ }^{4}$ and MOPAC ${ }^{5}$ into IVIChem. Here, it is extended to $a b$ initio $\left(\mathrm{GAMESS}^{6}\right)$, DFT (deMon2 $\mathrm{k}^{7}$ ), and tight binding $\left(\right.$ deMon-nano $\left.{ }^{8}\right)$ packages.

In addition to $\mathrm{CC}$ codes, chemistry free web software have been integrated into IVIChem; for instance, the last version of JChemPaint ${ }^{9}$ and the $\mathrm{Jmol}^{10}$ programs were built-in to make easy the molecular structure input in 2D and 3D pictures. This last program was modified $^{11}$ to include tool bars to facilitate many actions in the molecular construction. In addition, OpenBabel ${ }^{12}$ is employed; it allows the coordinate conversion to different appropriate formats. Collections of output data are analyzed by graphing selected values using a crossplatform software package for creating scientific plots (Ptplot ${ }^{13}$ program) or offering the possibility of using Excel type facilities.

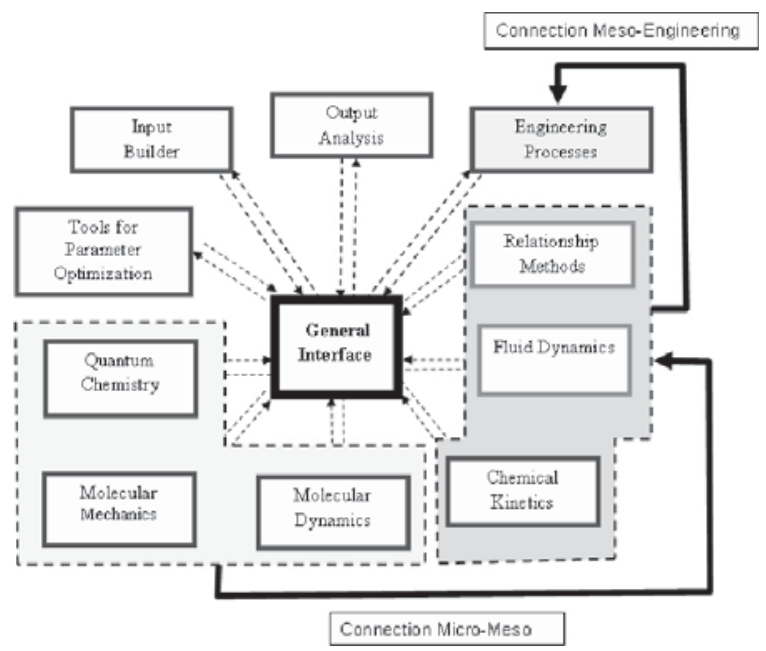

Fig. 1. Scheme of a general interface for modeling micro, meso and engineering processes.

A variety of computing languages in the development of IVIChem have been used, such as HTML5, PHP, Java Script, Phyton, CSS, XML, Bash, and Java.

\section{BUILDING INPUT FILES AND SUBMITTING}

The first view after login IVIChem is a screen with options, such as: "Create job", "Multi analysis" of outputs, "Relocate" and "Delete" outputs, with a list of directories to browse jobs and a button in the right up site of the screen for update job status. In the case of "Create job" option, two possibilities are considered, one of them is "Draw geometry" and other "From XYZ cords", as shown in Fig. 2.

One interesting feature introduced in this version is the possibility to make multiple calculations with very fast codes in a single job; e.g., to evaluate elementary processes in a surface. Thus, evaluation of potential 
energy curves, surfaces, and volumes (PEC, PES, and PEV) for adsorption, diffusion, search for structures close to the transition state, and surface reactions were implemented in MOPAC and CATIVIC codes.

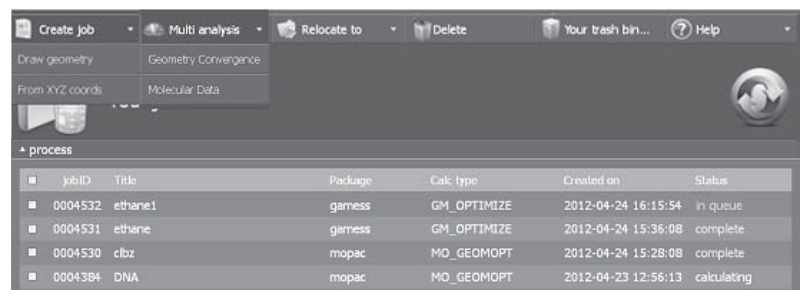

Fig. 2. First view after login IVIChem.

Once the input file has been dynamically built by drawing the molecular system or by introducing the molecular coordinates and after the keyword specifications, the job may be submitted to the calculation queue simply by clicking the button "Send to queue", which is shown in the top of Fig. 3.

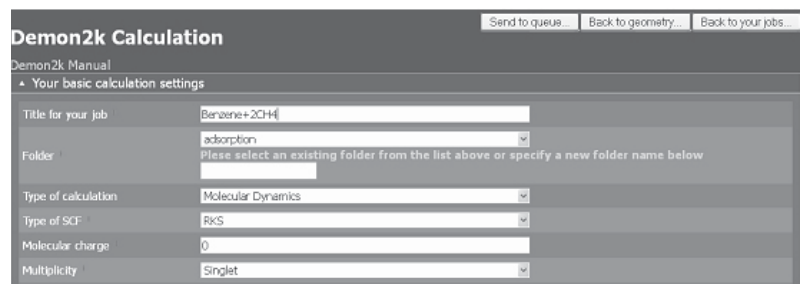

Fig. 3.Creating an input for DeMon2k code.

\section{Analyzing Output}

Three different tools for analysis have been partially put into practice: (a) one that corresponds to "Multi analysis", i.e., analysis of multiple output jobs of the same type (see Fig. 2). (b) single-job calculation, and (c) multiple calculations in a single job (process). Multi analysis has until now two options: "Geometry Convergence" and "Molecular Data" as show in Fig. 3 . In the first case, the result is a graph with converge energies (gradients) for different steps is displayed in a 2-D graph for each selected job. In the second case, a table with values of total energy, HOMO and LUMO energies and dipolar moment is shown. Two columns of this table can be plotted in 2-D using the UC Berkeley's PtPlot, according with the selection of the user. This analysis has been implemented in the actual interface for all considered codes.

As mentioned above, multiple calculations with MOPAC code to study the analysis of adsorption or interaction was performed. As an example, $\mathrm{CH} 3$ interaction with benzene was carried out by evaluating the potential energy. Once a process is performed appears in the job browser the status "complete"; then clicking on the job name, the option "global molecular properties (process)", appears for the analysis of results, as shown in Fig. 4.

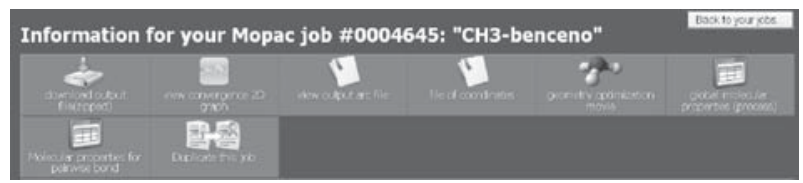

Fig. 4. Options for analysis of results of a single optimization job.

A selection of bond atoms is directly performed by picking with the cursor atoms in the JMOL picture that appear after selection of "global molecular properties (process)". This will create a table that includes the internuclear distance and charges on two previously selected atoms, total energy, heat of formation, dipolar moment, HOMO and LUMO energies, delta of energy respect to the most stable calculation for each point of the process, as shown in Fig. 5. At the bottom of the interface page, it was included the possibility to save the table on your computer and to use an Excel type program in order to make a graph, as it is shown for the plot of Total Energy vs. C13-C6 inter-nuclear distance at the end of this Figure.

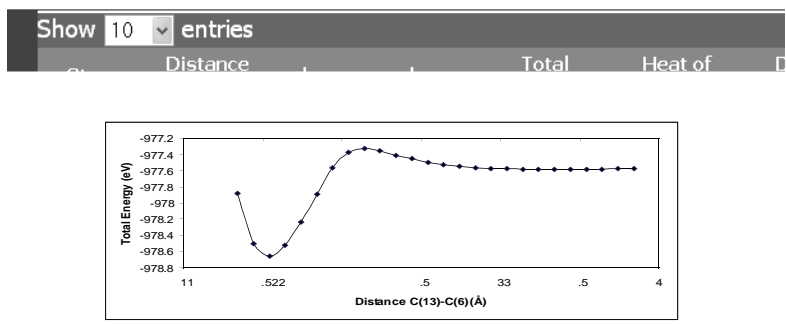

Fig. 5. Table of molecular global properties.

In addition to the feasibility to analyze formation and breaking bonds, it is possible the duplication of the job input, download the output, to see the file of coordinates, and to use them in other calculations, see arc files (for MOPAC), also the view of the starting and final 
geometries for each step of the process that are visualized in the "geometry optimization movie" option, see Fig. 4.

\section{INTERFACE FOR ADMINISTRATOR AND INCLUSION OF NEW CC CODES}

The addition of other CC calculation codes is the most imperative issue to IVIChem in order to grow its potentiality. A partially automatic interface was generated with XML, Java Script and PHP codes to experts and $\mathrm{CC}$ software creators. Here, the name of the package, its prefix, type of coordinates selected, and the number of calculation types and keywords are required. For each type of calculation, there are an arbitrary number of text fields, check boxes (on/off switches), select fields (drop-down option lists), and text areas. Furthermore, administration functions include adding, browsing, and editing the information of IVIChem's users with the report of collaborating institutions.

\section{Conclusions and Comments}

It is possible to create user interface software for multidisciplinary area in CC. However, in spite of the effort, too much work it is necessary to accomplish the proposed scheme given in the introduction, Fig. 1. It requires interface layers, database constructions, and new $\mathrm{CC}$ codes related with engineering processes. In particular, it is also necessary to include different molecular mechanics programs using different types of force fields.

Acknowledgments: The authors gratefully acknowledge the support of the Venezuelan LOCTI research program.

\section{References}

Baldridge KK, Greenberg JP, Sudholt W, Mock S, Altintas IY, Amoreira C, Potier Y, Birnbaum A, Bhatia K, Taufer M (2005) Proceedings of the IEEE 93: 510-521.

Podolyan Y, Leszczynski J (2009) In J Quantum Chem 109: 8-16.

Sojo V, Peraza A, Ruette F, Sánchez M, Acosta AE, J. Comp. Meth. Sci. Eng. (in press).

Ruette F, Sánchez M, Martorell G, González C, Añez R, Sierraalta A, Rincón L, Mendoza C (2004) Int J Quantum Chem 96: 321-332.

Stewart JP (1990) J Computer-Aided Mol Design 4: 1-103.
Schmidt MW, Baldridge KK, Boatz JA, Elbert ST, Gordon MS, Jensen JH, Koseki S, Matsunaga N, Nguyen KA, Su SJ, Windus TL, Dupuis M, Montgomery JA (1993) J Comput Chem 14: 1347-1363.

Köster AM, Calaminici P, Casida ME, Dominguez VD, FloresMoreno R, Geudtner G, Goursot A, Heine T, Ipatov A, Janetzko F, del Campo JM, Reveles JU, Vela A, Zuniga B, Salahub DR (2009) deMon2k, Version 3, The demon developers, Cinvestav, México-City.

Heine T, Rapacioli M, Patchkovskii S, Frenzel J, Koster A, Calaminici P, Duarte HA, Escalante S, Flores-Moreno R, Goursot A, Reveles J, Salahub D, Vela A (2009) deMon-Nano Experiment, http://physics.jacobs-university.de/theine/research/deMon/.

Kuhn S (2006) An Applet Release of JchemPaint, CDK News, 3, pp. 21-23.

Jmol. Jmol: an open-source Java viewer for chemical structures in 3D. [Online] August 11, 2010. [Cited: October 17, 2010] http:// jmol.sourceforge.net/.

Matheus E, Undergraduate Thesis of Computer Science, Universidad Central, Caracas, Venezuela (2012).

Open Babel, The Open Source Chemistry Toolbox, [Online] Septiembre 29, 2010. [Cited: April 25, 2011] http://openbabel. org/.

Berkeley EECS Dept. Ptplot. Ptolemy Project. [Online] UC Berkeley, 20 Octubre 2010. [Cited: 29 April 2011.] http://ptolemy. eecs.berkeley.edu/java/ptplot/.

Morella Sánchez', Alexander Peraza', Víctor Sojo ${ }^{4}$, Eleazar Matheus ${ }^{2}$, Ernesto Coto ${ }^{2}$, Miguel Fernández ${ }^{3}$, Rhonald López', Marbelia López ${ }^{1}$ \& Fernando Ruette ${ }^{{ }^{*}}$

\footnotetext{
${ }^{1}$ Laboratorio de Química Computacional, Centro de Química, Instituto Venezolano de Investigaciones Científicas (IVIC).

${ }^{2}$ Facultad de Ciencias, Escuela de Computación, Universidad Central de Venezuela.

${ }^{3}$ Facultad de Ciencias, Universidad de Carabobo.

${ }^{4}$ CoMPLEX, University College London. London, UK.

*e-mail: fruette@ivic.gob.ve
} 